\title{
Analisis Eksternal Humas Kapendam Jaya TNI AD dalam Membangun Community Relations pada Generasi Milenial
}

\author{
Yenny Octavia dan Sinta Paramita \\ yennyoctavia20@gmail.com; sintap@fikom.untar.ac.id \\ Fakultas Ilmu Komunikasi Universitas Tarumanagara
}

\begin{abstract}
In order to run one of the main functions of The National Army of Indonesia (TNI), namely defense, TNI runs the external function of public relations, which is directly done by Pendam Jaya TNI AD under the leadership of Kristomei Sianturi, S.Sos., M.Si (Han) as the Head of Pendam Jaya. Pendam as the part of governmental agencies public relations focuses on running the function of public relations instead of profit. This research aims to analyze the external activities of TNI AD Public Relations for establishing relationship with millennial generation and the correlation with public relations external function namely community relations. The theories used in this research are about communication, group, and community relations. This research is conducted qualitatively with descriptive case study. The data is obtained from deep interview with the Head of Pendam TNI AD and interview with four of his staff. As the conclusion, public relations external activities conducted by Pendam TNI AD is the effort to establish and improve the foundation of millennial generation as the generation which will be needed by this nation soon.
\end{abstract}

Keywords: Public Relations of TNI, Kapendam Jaya, Community Relations, Millennial Generation, youth.

\begin{abstract}
Abstrak
Dalam rangka menjalankan salah satu fungsi utama TNI yakni, pertahanan, TNI menjalankan fungsi eksternal Humas yang dilaksanakan langsung oleh Penerangan Kodam (Pendam) Jaya TNI AD dibawah kepemimpinan Kristomei Sianturi, S.Sos., M.Si (Han) selaku Kapendam Jaya. Pendam sebagai bagian dari humas instansi pemerintahan tidak berfokus pada profit. Namun bagaimana menjalankan fungsi dari Humas. Penelitian ini bertujuan untuk mengetahui serta menganalisis aktivitas eksternal dari Humas TNI AD untuk menjalin hubungan terhadap generasi milenial dan kaitannya dengan fungsi eksternal Humas yaitu community relations. Teori yang digunakan dalam penelitian ini adalah teori komunikasi, komunikasi kelompok, dan community relations. Metode penelitian yang digunakan ialah kualitatif studi kasus secara deskriptif. Data yang diperoleh melalui wawancara mendalam dengan Kapendam TNI AD dan wawancara terhadap empat jajarannya. Kesimpulan dari penelitian ini ialah aktivitas eksternal Humas yang dilakukan oleh Pendam Jaya TNI AD merupakan upaya untuk memupuk dan memperbaiki pondasi generasi milenial sebagai generasi yang akan dibutuhkan bangsa ini di kemudian hari.
\end{abstract}

Kata Kunci: Humas TNI AD, Kapendam Jaya, Community Relations, Generasi Milenial, Kaum Muda.

\section{Pendahuluan}

Sebagai sebuah instansi kepercayaan masyarakat, TNI harus dapat memprediksi ancaman sehingga dapat diantisipasi sejak dini agar kedaulatan dan keutuhan negara dapat terjaga. Untuk mencegah ancaman yang kemungkinan datang 
secara internal di masa mendatang, maka TNI menentukan salah satu target utamanya yakni, generasi muda. Generasi muda Indonesia tidak terlepas dari tuntutan dan tantangan tugas kedepan yang tidak semakin ringan, bahwa pada saat ini dan kedepan ancaman bangsa Indonesia sudah memasuki semua aspek kehidupan berbangsa dan bernegara. TNI memegang andil penting untuk mempersiapkan generasi muda (diakses dari: http://indonews.id, pada tanggal 20 November 2018, pukul 15:00 WIB).

TNI memiliki divisi yang secara khusus yakni Penerangan Kodam yang melakukan tugas dan fungsi pencitraan TNI AD baik secara tertutup maupun secara terbuka, agar nama TNI AD tetap terpercaya di dalam masyarakat (diakses dari: https://tniad.mil.id, pada tanggal 23 November 2018 pukul 15:00 WIB).

Penerangan Kodam pada tingkat Kodam Jaya bertugas langsung dalam mempersiapkan generasi muda serta menyebarkan informasi berupa fakta. Pendam sebagai pengemban fungsi penerangan merupakan ujung tombak dalam perang informasi. Pendam memiliki salah satu tugas untuk melakukan penerangan umum yaitu, tugas yang dilakukan yakni terkait penyelenggaraan segala usaha, pekerjaan dan kegiatan perencanaan, persiapan, pelaksanaan, pengawasan dan pengendalian penyebaran informasi berupa fakta atau realita tentang Angkatan Darat di wilayah Kodam ke masyarakat.

Pendam Jaya dipimpin oleh seorang Kepala Penerangan Kodam Jaya. Kapendam sebagai perwira staf khusus Pangdam bertugas untuk menjalin, memelihara dan meningkatkan kerja sama dengan mitra kerja, media massa dan komunitas penerangan serta melaksanakan hubungan timbal balik dengan masyarakat (diakses dari: http://www.kodam5-brawijaya.mil.id, pada tanggal 23 November 2018 pukul 15:00 WIB).

Berdasarkan pemaparan diatas mengenai Kapendam Jaya, penulis merasa tertarik untuk melakukan penelitian tentang analisis eksternal Humas Kapendam Jaya TNI AD dalam membangun Community Relations pada generasi milenial. Penelitian ini meneliti bagaimana Kapendam Jaya melakukan fungsi eksternal humas terhadap generasi milenial yang mendominasi kehidupan bermasyarakat saat ini.

Berdasarkan latar belakang yang telah dipaparkan, maka perumusan masalah peneliti adalah sebagai berikut "Bagaimana Analisis Eksternal Humas Kapendam Jaya TNI AD dalam Membangun Community Relations pada Generasi Milenial".

Tujuan penelitian ini untuk mengetahui bagaimana Analisis Eksternal Humas Kapendam Jaya TNI AD dalam Membangun Community Relations pada Generasi Milenial.

Berdasarkan kerangka teori pada Gambar 1 dibawah, beberapa teori yang menjadi dasar penelitian penulis yaitu, komunikasi kelompok, humas atau public relations, community relations, dan generasi milenial. Pemilihan teori-teori ini didasari kesesuaiannya terhadap judul penelitian penulis. Sebagai salah satu lembaga pemerintahan, humas TNI yang dalam struktur organisasinya disebut Penerangan Kodam (Pendam) merupakan organisasi nonprofit. Untuk itu, langkah dan tujuan yang dilakukan Pendam tidak berbasis pada mencari keuntungan pribadi. Langkahlangkah dalam community relations bagi organisasi non-profit menurut DeMartinis (2004:2-4) diantaranya, merumuskan komunitas organisasi dan berbagai kelompok yang ada di dalamnya, menentukan tujuan program community relations organisasi, menyusun pesan yang hendak disampaikan, memilih metode yang paling baik dalam penyampaian pesan, melaksanakan program community relations organisasi, serta menganalisis hasil (dalam Iriantara, 2007: 87-88). 
Yenny Octavia, Sinta Paramita: Analisis Eksternal Humas Kapendam Jaya TNI AD dalam Membangun Community Relations Pada Generasi Milenial

Gambar 1: Kerangka Pemikiran

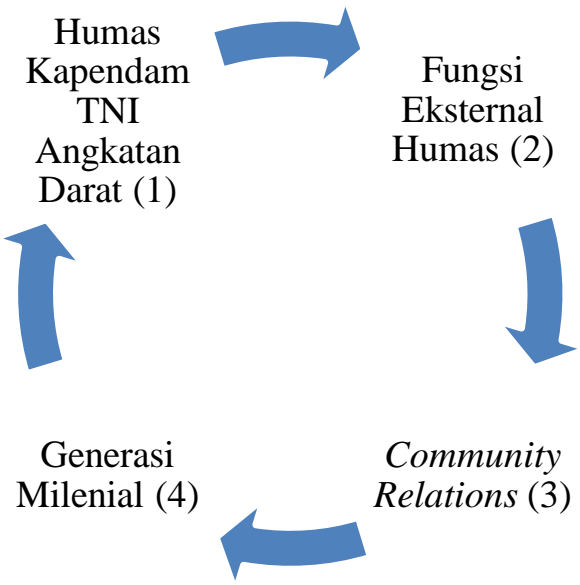

Penelitian yang dilakukan oleh Farleni dan Widyatmoko yang berjudul "Peran Public Relations Kepolisian Indonesia melalui Media Relations dalam Membangun Citra yang Lebih Baik“ vol 6. No. 1 pada 2014 lalu menjadi acuan bagi penulis dalam melakukan penelitian serupa. Penelitian yang membahas mengenai bagaimana peran Public Relations Kepolisian Republik Indonesia membangun citra baik dengan menjalin hubungan kemitraan dengan media. Dalam membangun citra, Kepolisian Republik Indonesia melalui Public Relations. Sebagai bagian dari instansi pemerintahan, Humas Kepolisian tidak berfokus pada profit atau keuntungan. Humas Kepolisian berupaya memanfaatkan fungsi dari hubungan masyarakat (humas) dengan melakukan kerja sama dengan berbagai media, baik cetak maupun media elektronik. (diunduh dari: journal.untar.ac.id, pada tanggal 16 September 2018 pukul 13:00 WIB).

Adapun, penelitian yang dilakukan oleh Yugih Setyanto, S.Sos., M.Si dan Septia Winduwati, S.Sos, M.Si yang berjudul "Manfaat Public Relations dalam Membangun Reputasi Sekolah (Pemahaman Fungsi Public Relations di SMA 1 Tanjung Pandan Belitung)" yang juga turut menjadi acuan bagi penulis. Penelitian yang meneliti bagaimana sebuah instansi menjalankan fungsi Public Relations guna membangun reputasi sekolah. Dalam penelitian ini, didapatkan bahwa perlu adanya kombinasi yang saling menguntungkan antara pihak sekolah secara internal ataupun pihak pengguna jasa (murid dan orang tua murid) yang punya andil yang sama untuk membangun reputasi sekolah yang lebih positif (Setyanto \& Winduwati, 2016).

\section{Metode Penelitian}

Penelitian ini menggunakan metode penelitian kualitatif deskriptif dengan pendekatan studi kasus, dimana peneliti hanya akan memaparkan situasi atau peristiwa dan tidak mencari dan menjelaskan hubungan serta tidak menguji hipotesis atau membuat prediksi. Studi kasus memungkinkan peneliti untuk mempertahankan karakter berpikir secara menyeluruh dengan mempertimbangkan segala aspek yang mungkin memengaruhi tingkah laku sebagai suatu kesatuan yang utuh.

Untuk memperkuat data penelitian, maka digunakan metode pengumpulan data dengan wawancara, studi pustaka, dokumentasi serta penelusuran data online. Narasumber yang dipilih penulis dalam wawancara, yaitu: 
1. Kolonel Inf. Kristomei Sianturi, S,Sos., M.si (Han) selaku Kepala Penerangan Kodam Jaya yang dijabat sejak tahun 2017 hingga saat ini.

2. Letnan Kolonel Adrian Ponto S.H., seorang informan pertama yang menduduki jabatan sebagai Wakapendam.

3. Mayor Inf. Albertus Hernanto, informan kedua yang menjabati posisi Kasilissa yang membuat sambutan dan amanat untuk Pangdam.

4. Mayor Inf. Saliman, informan ketiga yang menduduki posisi sebagai Kasipensat yang bertugas dalam membuat majalah Jayakarta.

5. Kapten Arh. Simon Edward Sirait, S.Pd., sebagai Kasimedia Elektronik

Teknik analisis data dalam penelitian ini adalah deskriptif-kualitatif seperti pernyataan Bogdan dan Bikien yang menyatakan bahwa analisis data kualitatif adalah upaya yang dilakukan untuk bekerja dengan data, mengorganisasikan data, memilah-milah menjadi satuan yang dapat dikelola, mensistesiskannya, mencari dan menemukan pola, menemukan apa yang penting dan apa yang dipelajari dan memutuskan apa yang dapat diceritakan pada orang lain (dalam Moleong 2013:248). Menurut Sugiyono, aktivitas dalam analisa data dibagi menjadi tiga (Sugiyono, 2011:337), yakni:

1. Reduksi data

Dalam mereduksi data, langkah pertama yang perlu dilakukan adalah melakukan editing, meringkas dan mengelompokkan data. Kemudian data yang diperoleh ditulis dalam bentuk laporan atau data yang terperinci.

2. Penyajian data

Langkah-langkah pengorganisasian data dilibatkan dalam penyajian data. Data yang diperoleh dikategorisasikan menurut pokok permasalahan dan dibuat dalam bentuk matriks sehingga memudahkan peneliti untuk melihat pola-pola hubungan satu data dengan yang lainnya.

3. Penarikan serta pengujian kesimpulan

Setelah melakukan kegiatan-kegiatan sebelumnya, langkah selanjutnya ialah menyimpulkan dan melakukan verifikasi data-data yang sudah diproses kedalam bentuk-bentuk yang sesuai dengan pola pemecahan permasalahan yang dilakukan. Kemudian melakukan pelaporan hasil penelitian lengkap dengan temuan baru yang berbeda dari temuan yang sudah ada.

\section{Hasil Temuan dan Diskusi}

Berdasarkan hasil wawancara yang dilakukan oleh penulis kepada narasumber utama yakni, Kepala Penerangan Kodam Jaya, Kolonel Inf. Kristomei Sianturi, S,Sos., M.si (Han), dalam tugasnya membangun hubungan dengan generasi milenial melalui kegiatan community relations guna mencapai tujuan seperti yang telah ditetapkan oleh Pendam. Pendam melihat adanya perubahan signifikan yang dirasakan oleh anak-anak pada zaman dahulu dengan anak-anak masa kini. Saat ini perubahan teknologi dan komunikasi memiliki pengaruh yang sangat besar terutama berkaitan dengan penanaman nilai-nilai. Ini menjadi salah satu alasan utama Pendam semakin banyak melakukan pendekatan terhadap generasi muda. Berikut penjabarannya:

Sesuai dengan langkah-langkah dalam Community Relations bagi organisasi nonprofit menurut DeMartinis (dalam Iriantara, 2007: 87-88), diantaranya ialah.

1. Merumuskan komunitas organisasi dan berbagai kelompok yang ada di dalamnya. 
Yenny Octavia, Sinta Paramita: Analisis Eksternal Humas Kapendam Jaya TNI AD dalam Membangun Community Relations Pada Generasi Milenial

Dalam merumuskan komunitas organisasi dan berbagai kelompok bagi organisasi nonprofit Pendam tidak menentukan secara langsung. Hal ini seperti penjelasan dari Wakapendam, Letnan Kolonel Adrian Ponto S.H., dalam wawancaranya yang memaparkan bahwa perumusan komunitas organisasi dan berbagai perencanaan di dalamnya itu tidak berada di tingkat Penerangan Kodam karena kegiatan tersebut berada pada tingkat Mabes. Sehingga tugas dari bagianbagian yang berada di Pendam ialah melaksanakan program dari Komando Atas. Program ini berbentuk direktif atau pedoman terarah yang perlu dikembangkan oleh Pendam agar tepat sasaran yang salah satunya ditujukan kepada generasi muda. Direktif ini yang kemudian diolah menjadi sebuah aktivitas yang dilaksanakan langsung oleh Kapendam beserta jajarannya.

Generasi muda ini menjadi salah satu target dari aktivitas eksternal humas Kapendam yang dalam Bab II telah dipaparkan mengenai teori perbedaan generasi oleh Yanuar. Menurut Yanuar, Generasi Y adalah generasi yang dikenal dengan sebutan generasi milenial yang tahun kelahirannya dimulai dari tahun 1980 hingga 1995. Generasi milenial memiliki karakteristik masing-masing individu yang berbeda tergantung dimana ia dibesarkan, strata ekonomi, dan sosial keluarganya. Selain itu pola komunikasinya sangat terbuka dibanding dengan generasi-generasi sebelumnya (diunduh dari: jurnal.stieama.ac.id, pada tanggal 16 November 2018 pukul 11:00 WIB).

2. Menentukan tujuan program Community Relations organisasi.

Menentukan tujuan program membuat organisasi dapat mengetahui apa yang menjadi arah dari pembuatan program tersebut. Setelah mengembangkan dan merencanakan direktif dari Pangdam, Pendam harus tetap berpegang teguh pada tujuan dari hasil yang ingin dicapai. Sesuai dengan penuturan Kolonel Inf. Kristomei Sianturi, S,Sos., M.si (Han) dalam wawancaranya, dapat disimpulkan bahwa tujuan utama dari program Community Relations yang dilaksanakan oleh Kapendam ialah untuk memperkuat pondasi kebangsaan agar tidak mudah disusupi, dan dipengaruhi oleh aliran tertentu.

Hal ini juga bertujuan agar nilai-nilai dari Pancasila sebagai dasar ideologi negara tidak bergeser ataupun berubah, karena nilai itulah yang dicita-citakan oleh para pendiri bangsa Indonesia. Hal ini berdasarkan kesadaran Pendam Jaya TNI Angkatan Darat bahwa generasi milenial harus diperkuat dengan nilai Pancasila karena generasi ini yang dalam kurun waktu sepuluh hingga dua puluh tahun kedepan mengendalikan negara Indonesia.

3. Menyusun pesan yang hendak disampaikan.

Pesan yang disusun untuk setiap kelompok komunitas berbeda-beda karena setiap kelompok memiliki karakteristik yang tidak sama. Pesan yang hendak disampaikan harus dapat mencapai tujuan yang telah disusun sebelumnya sehingga program dapat terlaksana dengan baik. Pesan kepada generasi milenial untuk melandasi pemikiran dengan cinta tanah air, berkarya untuk bangsa serta menjaga keutuhan NKRI tanpa menjadi penyebar isu-isu kebohongan atau menjadi pihak yang dengan sengaja menyebarkan kebencian terutama melalui suku, ras maupun agama.

Dengan memperkuat pondasi dari pemahaman generasi ini, kesenjangan yang mungkin terjadi dapat diminimalisir sehingga isu-isu yang menggunakan kampanye hitam dan memanfaatkan media internet tidak tersebar dengan mudah. Banyaknya pesan yang ingin disampaikan ini dikemas dalam satu kesatuan aktivitas yang menarik namun juga sarat akan nilai dan pesan baik secara moral maupun dalam prakeknya. 
4. Memilih metode yang paling baik dalam penyampaian pesan.

Generasi milenial sendiri adalah generasi yang sangat mudah menyesuaikan diri dengan perkembangan teknologi dan informatika. Perbedaan ini sangat terlihat jelas jika dibandingkan dengan generasi terdahulunya, sehingga perlu ada penyesuaian agar pesan yang disampaikan melalui metode tersebut dapat tepat sasaran seperti yang dipaparkan oleh Kapendam dalam wawancaranya dengan penulis. Dalam menjalankan programnya, Kapendam menjelaskan bahwa tidak ada metode-metode yang baku karena terus menyesuaikan dengan perkembangan zaman dan perkembangan dari target sasarannya.

Metode tatap muka menjadi cara yang digunakan Kapendam dalam mendekatkan diri dengan milenial. Tidak ada metode yang paling baik dalam penyampaian pesan, yang dimaksudkan dari hal ini ialah bahwa cara bertindak yang dilakukan Pendam jika kurang berdampak terhadap masyarakat akan segera diubah dengan cara bertindak yang lainnya dalam arti lain perencanaan kedua yang disiapkan. Pada umumnya dampak yang jelas dan dapat langsung terlihat yaitu dari minat peserta dalam mengikuti program serta antusiasme dalam melakukan interaksi dua arah dengan Pendam.

\section{Melaksanakan program Community Relations organisasi}

Menurut DeMartinis (2004: 2-4), perencanaan memang penting. Namun, pelaksanaan juga perlu diperhatikan agar sesuai dengan perencanaan. Baik atau buruknya hasil dari perencanaan dapat terukur melalui tahap pelaksanaan dari program yang telah disusun. Dalam pelaksanaan program-programnya, Kapendam lebih memilih untuk menghidupkan suasana agar menjadi lebih santai dan memilih kegiatan yang membuat para generasi milenial lebih tertarik. Pengajaran Bahasa Inggris yang disisipi nilai-nilai yang ingin ditanamkan kepada generasi milenial seperti nilai Pancasila mendapat antusiasme yang cukup tinggi dari generasi muda ini. Target audiens belajar Bahasa Inggris, namun tanpa sadar juga mempelajari dan menyerap nilai-nilai yang sengaja disisipkan dalam setiap pembelajaran.

6. Menganalisis hasil

Hasil merupakan panduan antara keberhasilan dan kegagalan (Iriantara, 2007: 88). Namun, menilik dari pernyataan Kapendam dan jajarannya selama wawancara didapatkan bahwa kegiatan community relations yang telah dijalankan sejak TNI berdiri telah mengalami peningkatan drastic. TNI Angkatan Darat pernah mengalami kemunduran yang terjadi pasca reformasi. Kemunduran ini tidak mengecilkan semangat dari TNI untuk bangkit kembali dan menjalankan fungsi pertahanannya demi keberlangsungan negara Indonesia.

Melalui pernyataan Kasilissa, Mayor Infanteri Albertus Hernanto dalam wawancaranya dengan penulis, menyatakan bahwa evaluasi hasil dari program yang telah berlangsung sudah efektif namun belum maksimal. Untuk itu, program lanjutan dari Pendam akan menyasar dunia akademisi mengingat dunia ini adalah dunia yang sarat akan pengajaran nilai-nilai sejak usia dini. Untuk itu, jika program TNI dapat menjadi bagian dari program akademisi, maka tujuan yang ingin dicapai TNI untuk merangkul generasi milenial melalui Pendam Jaya akan menjadi lebih mudah tercapai. Selain itu, melalui evaluasi hasil didapatkan bahwa kerja sama Pendam TNI dengan para praktisi akademis mulai dari tingkat sekolah dasar hingga perkuliahan dapat menjadi kunci untuk membuat program Kapendam Jaya tepat pada sasarannya. 
Yenny Octavia, Sinta Paramita: Analisis Eksternal Humas Kapendam Jaya TNI AD dalam Membangun Community Relations Pada Generasi Milenial

\section{Simpulan}

Kesimpulan yang didapat oleh penulis dalam penelitian ini ialah telah terjawabnya rumusan masalah dan tujuan penelitian. Dalam membangun community relations pada generasi milenial melalui peran eksternal humas, Kapedam Jaya TNI AD berupaya untuk melakukan interaksi kepada masyarakat terutama kepada generasi milenial secara langsung. Pesan-pesan yang disampaikan melalui setiap aktivitas eksternal Humas sarat akan nilai-nilai nasionalisme dan cinta tanah air yang ingin ditumbuhkan kepada generasi muda.

Selain dari nilai tersebut, Kapendam juga menanamkan nilai keagamaan. Nilai keagamaan ini dimaksudkan untuk memperkuat integritas generasi milenial agar dapat membedakan secara nurani apa yang baik dilakukan dan tidak baik untuk dilakukan. Selain itu, metode pendekatan terhadap generasi milenial yang digunakan tidak baku dan dapat berubah sesuai dengan situasi dan kondisi. Penyampaian disertai kegiatan yang santai namun tetap serius dan menarik menjadi fokus dari penyusunan kegiatan Kapendam Jaya.

Aktivitas eksternal Humas Kapendam Jaya menggunakan pendekatan yang membutuhkan interaksi secara langsung kepada milenial. Untuk itu, kegiatan yang rutin dilakukan ialah mengisi perkuliahan di universitas-universitas yang menjalin kerja sama dengan Pendam.

\section{Ucapan Terima Kasih}

Penulis mengucapkan terima kasih kepada pejabat Fikom UNTAR, kemudian Ibu Sinta Paramitha S.I.P., M.A., selaku dosen pembimbing utama skripsi, kepada narasumber yang bersedia untuk diwawancara serta kepada seluruh pihak yang telah membantu penulis menyelesaikan penulisan skripsi ini baik secara langsung maupun tidak langsung.

\section{Daftar Pustaka}

Farleni, \& Widyatmoko. (2017). Peran Public Relations Kepolisian Republik Indonesia Melalui Media Relations Dalam Membangun Citra Yang Lebih Baik. Jurnal Komunikasi Universitas Tarumanagara, 12-23.

hendro. (2018, November 22). Aster Panglima TNI: Generasi Muda Indonesia Perlu Miliki Mental Ideologi. Retrieved from indonews.id: http://indonews.id/artikel/17452/Aster-Panglima-TNI-Generasi-MudaIndonesia-Perlu-Miliki-Mental-Ideologi/

Iriantara, Y. (2007). Community Relations: Konsep dan Aplikasinya. Bandung: Simbiosa Rekatama Media.

Kodam Brawijaya. (2014, January 22). Tugas Pokok Pendam. Retrieved from Kodam 5 Brawijaya: http://www.kodam5brawijaya.mil.id/berita/detail/567/tugas-pokok-pendam.html

Kodam Jaya. (2018, Desember). Retrieved from Kodam Jaya/Jayakarta: https://kodamjaya-tniad.mil.id/

Moleong, L. J. (2013). Metodologi Penelitian Kualitatif Edisi Revisi. Bandung: PT. Remaja Rosdakarya. 
Putra, Y. S. (2016). Theoritical Review : Teori Perbedaan Generasi. Among Makarti, 129.

Setyanto, Y. S., \& Winduwati, S. S. (2016). Manfaat Public Relations dalam Membangun Reputasi Sekolah (Pemahaman Fungsi Public Relations di SMA 1 Tanjung Pandan Belitung). https://www.researchgate.net/publication/309854143_Manfaat_Public_Relat ions_dalam_Membangun_Reputasi_Sekolah_Pemahaman_Fungsi_Public_R elations_di_SMA_1_Tanjung_Pandan_Belitung (p. 10). Sumatera Barat: Research Gate.

TNI AD. (n.d.). Peran, Fungsi dan Tugas. Retrieved from Website TNI AD: https://ni.mil.id/pages-2-peran-fungsi-dan-tugas.html 